\title{
Myocardial damage induced by a single high dose of isoproterenol in C57BL/6J mice triggers a persistent adaptive immune response against the heart.
}

Elvira Forte ${ }^{1}$, Mona Panahi ${ }^{2}$, Fu Siong $\mathrm{Ng}^{2}$, Joseph J. Boyle ${ }^{2}$, Jane Branca ${ }^{1}$, Olivia Bedard ${ }^{1}$, Muneer G. Hasham ${ }^{1}$, Lindsay Benson ${ }^{3}$, Sian E. Harding ${ }^{2}$, Nadia Rosenthal ${ }^{1}$, Susanne Sattler ${ }^{2}$.

\author{
Affiliations: \\ ${ }^{1}$ The Jackson Laboratory, 600 Main Street, Bar Harbor, ME 04609, USA \\ ${ }^{2}$ National Heart and Lung Institute, Imperial College London, London, W12 ONN, UK \\ ${ }^{3}$ Central Biomedical Services, Imperial College London, London, W12 0NN, UK
}

\section{Corresponding author:}

Susanne Sattler

email: s.sattler@imperial.ac.uk

ORCID: http://orcid.org/0000-0001-9932-4109

\begin{abstract}
Heart failure is the common final pathway of a range of conditions resulting in myocardial damage and a major cause of morbidity and mortality worldwide. Strategies to improve tissue repair and prevent heart failure thus remain an urgent clinical need. Recent studies have documented activation of the adaptive immune system in response to myocardial damage and have implicated anti-heart autoimmunity in the development of heart failure. In an attempt to target anti-heart autoimmune responses as new therapeutic avenue, the number of experimental studies using in vivo models of myocardial damage to study the ensuing immune response has surged.

The beta-adrenergic agonist isoproterenol-hydrochloride has been used for its cardiac effects in a variety of different dosing and administration regimes. Most prominently, low doses $(<10 \mathrm{mg} / \mathrm{kg} \mathrm{sc})$ over an extended time period induce cardiac hypertrophy and fibrosis. In addition, single injections of high doses $(>100 \mathrm{mg} / \mathrm{kg}$ ) induce cardiomyocyte necrosis and have been used to mimic acute myocardial necrotic lesions as seen in myocardial infarction (MI). However, despite significant resource and animal welfare advantages, concerns about offtarget effects and clinical relevance have so far limited uptake in the cardiovascular research community.
\end{abstract}

To assess suitability of the isoproterenol model for the analysis of chronic post-MI immunological readouts, we treated $\mathrm{C} 57 \mathrm{BL} / 6 \mathrm{~J}$ mice with a single intra-peritoneal bolus 
injection of $160 \mathrm{mg} / \mathrm{kg}$ isoproterenol. Our results confirm the presence of necrotic lesions in the myocardium with significant resemblance of the histopathology of Type $2 \mathrm{Ml}$. Kidneys develop mild fibrosis secondary to early cardiac damage, while other organs remain unaffected. Most importantly, we showed that isoproterenol treatment causes myocardial inflammation and fibrosis, activation of T cells in the heart-draining mediastinal lymph nodes, deposition of mature antibodies in the myocardium and the presence of auto-antibodies against the heart in the serum 12 weeks after the initial injury.

In summary, this simple and cost-effective experimental model with significant animal welfare benefits induces myocardial damage reminiscent of human Type $2 \mathrm{MI}$, which is followed by a persistent adaptive immune response against the heart. This makes it a suitable and high-throughput model to study pathological mechanisms of anti-heart autoimmunity as well as to test potential immunomodulatory therapeutic approaches.

\section{Introduction}

Clinical guidelines distinguish between myocardial injury and myocardial infarction (MI). While myocardial injury encompasses any type of acute myocardial damage such as necrosis induced by myocarditis, sepsis or endogenous catecholamines, $\mathrm{Ml}$ is defined as ischemic damage resulting from an insufficient myocardial oxygen supply ${ }^{12}$. Aherosclerotic vascular disease is a prominent cause of $\mathrm{MI}$, where disruption of an atherosclerotic plaque can prevent coronary blood flow through a given artery resulting in infarction of the dependent myocardium. This is referred to as Type $1 \mathrm{MI}$ (T1MI). Type $2 \mathrm{MI}$ (T2MI) is a heterogeneous syndrome that occurs in the absence of coronary artery disease (CAD) and an acute atherothrombotic coronary event. Instead, other conditions such as hypoxemia, hypo/hypertension, tachycardia or tachyarrhythmias lead to an imbalance between oxygen supply and demand ${ }^{3}{ }^{4}$. T2MI is a common but under-recognised clinical entity, with prevalence estimates of up to $58 \%$ of Ml patients ${ }^{5}$.

Importantly, improved intervention and treatment after myocardial damage have significantly increased immediate survival. However, the regenerative capacity of the adult heart is minimal and healing is achieved by fibrotic repair which replaces damaged myocardium with non-contractile scar tissue. This impairs cardiac function and $62.7 \%$ of $\mathrm{MI}$ patients develop heart failure within 6 years after infarction ${ }^{6}$. The early immune response to myocardial necrosis is crucial for quick tissue repair, but excessive inflammation is involved in 
the development of heart failure 78910 . Large amounts of cardiac self-antigens, including myosin and troponin, in a highly inflammatory environment activate the adaptive immune system. Auto-reactive T and B cells can be long-lived and have been suggested to cause ongoing low level tissue destruction ${ }^{11} 12$ hampering regenerative efforts and exacerbating development towards heart failure ${ }^{13}{ }^{14}$. There is an urgent need for better recognition and understanding of these autoimmune processes to prevent further myocardial damage. Investigation of the adaptive immune response to cardiac damage is a highly complex multidimensional process, which to date still needs in vivo experimentation. In rodents, surgical coronary artery ligation most prominently of the left anterior descending artery (LAD), is the most commonly used experimental model for human $\mathrm{T} 1 \mathrm{MI}{ }^{15}$. LAD ligation is induced during open chest surgery, an invasive low-throughput procedure associated with high mortality rates. The use of the ß-adrenergic agonist isoproterenol to induce cardiotoxicity and infarctlike lesions has been described over 50 years ago in rats ${ }^{16}{ }^{17}$. Fibrosis in response to isoproterenol treatment is related to cardiomyocyte necrosis. Necrotic cardiomyocytes are mostly localised in the sub-endocardium, numbers peak at $24 \mathrm{~h}$ and debris is removed by $48 \mathrm{~h}$ 18. Isoproterenol is now routinely used as a long term low-dose treatment to induce cardiac hypertrophy 192021 , and few research groups have also used it to induce acute infarct-like lesions by a one-off injection of higher doses 222324 . Importantly, the isoproterenol model recapitulates several of the salient feature of T2MI. Positive inotropic and chronotropic effects lead to increased myocardial oxygen consumption consumption and $\mathrm{Ca}^{2+}$ leakage causing cardiomyocyte necrosis 2425 , while tachycardia leads to a reduction in diastolic perfusion time and coronary blood flow ${ }^{26}$, collectively resulting in patchy acute myocardial damage and necrosis. Notably, it also mechanistically and pathologically models a pattern of injury termed inotrope-induced cardiac damage or pressor-injury or catecholamine-heart, seen in the cardiac transplant and terminal heart failure setting ${ }^{27}$.

Here we characterise the immunological effects of a one-off intra-peritoneal injection of isoproterenol as a simple, resource-efficient, highly reproducible and significantly less invasive alternative to surgical $\mathrm{Ml}$ induction. We show that $\mathrm{T}$ cell activation in the mediastinal lymph nodes and anti-heart auto-antibody production can be investigated without the need for invasive surgical procedures, as the adaptive immune system will respond to cardiac antigens released from necrotic tissue, irrespective of the original trigger of necrosis. 
Forte et al, Cardiac autoimmunity model

\section{Materials and Methods:}

Mice: All animal procedures carried out at Imperial College London were approved by the Imperial College Governance Board for Animal Research and in accordance with the UK Home Office Animals (Scientific Procedures) Act 1986 and Directive 2010/63/EU of the European Parliament on the protection of animals used for scientific purposes. All animal work carried out at The Jackson Laboratories were approved by The Jackson Laboratory Institutional Animal Care and Use Committee and were in accordance with national and international regulations. Mice used were 8- to 12 -week-old C57BL/6J males and females; control mice were age- and sex-matched. Mice were housed under SPF conditions (Imperial College London) or in conventional cages (The Jackson Laboratories) in temperature-controlled facilities on a $12 \mathrm{~h}$ light/dark cycle on standard diet.

Isoproterenol treatment and tissue harvest: Mice were treated with isoproterenol $\mathrm{HCL}$ (Sigma-Aldrich, St. Louis, MO, USA) in Dulbecco's phosphate-buffered-saline (DPBS; SigmaAldrich) by intraperitoneal injection once at a dose of $160 \mathrm{mg} / \mathrm{kg}$. Control mice were treated with DPBS at equivalent volume. Tissue was harvested 1 or 2 weeks post-injection. On the day of tissue collection, $200 \mathrm{ul}$ blood was collected. Blood was incubated on ice for 30

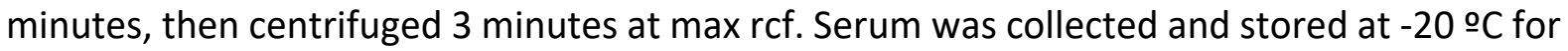
later use. Hearts and lymph nodes were isolated after in situ perfusion with ice-cold DPBS supplemented with $0.9 \mathrm{mM} \mathrm{CaCl} 2$ through the apex of the left ventricle of the heart to clear blood from heart chambers and blood vessels.

Histology and scoring of damage parameters: Organs of treated and untreated mice were excised after perfusion as described above, fixed in $10 \%$ neutral buffered formalin overnight, and stored in $70 \%$ ethanol. For wax-embedding and histology, tissue samples were dehydrated in an increasing gradient of ethanol and embedded in paraffin. Five $\mu \mathrm{m}$ sections were cut and de-waxed and rehydrated in an ethanol gradient. Sections were stained with hematoxylin and eosin (H\&E) and Picrosirius Red. All reagents were purchased from Sigma Aldrich (Sigma-Aldrich, Dorset, UK). Semi-quantitative scoring of heart sections was performed as established previously ${ }^{28}$. Hematoxylin \& eosin stained sections were used to analyse and score mononuclear cell infiltration in hearts. Picrosirius Red staining was used to analyse and score fibrosis in hearts and kidneys. Individual parameters were scored on a scale 
of 0 (none), 1 (mild), 2 (moderate) to 3 (severe). Scores were obtained from 4 areas each on two midline cross sections per animal by a blinded researcher. Images were captured using a LMD7000 microscope (Leica microsystems, Milton Keynes, UK) and processed for quantification of nuclei (cell count) and area of fibrosis using the public domain software ImageJ (NIH; http://rsb.info.nih.gov, $)^{29}$.

cTroponin and anti-heart autoantibody ELISA: A mouse cardiac troponin I (cTI) ELISA Kit (MyBioSource, San Diego, CA, USA) was used to determine cTI concentrations in postISOPROTERENOL serum as instructed by the manufacturer. Serum samples were diluted 2fold in supplied diluent. A standard curve was generated to calculate CTI concentrations in $\mathrm{pg} / \mathrm{ml}$.

The ELISA protocol for detection of mouse anti-heart auto-antibodies was optimised as described previously ${ }^{28}$. ELISA plates (SpectraMax Paradigm Molecular-Devices, UK) were coated with $50 \mu \mathrm{l}$ per well of $4 \mu \mathrm{g} / \mu \mathrm{l}$ pig heart lysate (Novus Biologicals, Bio-Techne, Abingdon, UK) diluted in PBS overnight at 4 으. Plates were washed three times for 5 minutes each with $200 \mu \mathrm{l}$ per well of ELISA washing buffer. $50 \mu \mathrm{l}$ of post-ISOPROTERENOL serum was added diluted 1:10 and 1:100 for overnight incubation at $4 \stackrel{\circ}{\circ}$. Detection reagents were anti-mouse IgG-HRP (all BioLegend, London, UK). Optical densities were measured at $450 \mathrm{~nm}$ using a SpectraMAX i3 microplate reader (Molecular Devices, San Jose, CA, USA).

Mediastinal lymph node flow cytometry: For isolation of single cells, mediastinal lymph nodes were manually minced through $70 \mu \mathrm{m}$ filters using the rubber end of a $1 \mathrm{ml}$ syringe. Red blood cells were lysed using Red Blood Cell Lysis buffer (Sigma-Aldrich, Dorset, UK) according to the manufacturer's instructions. The obtained cell mixture was then used for flow cytometric analysis. Antibodies used: anti-mouse CD45 (CD45-APC-Cy7 - cat. 103116, clone 30-F11, LOT B185138, dilution 1:800), anti-mouse CD3 (CD3-APC - cat. 100235, clone 17A2, LOT B166471, dilution 1:200), anti-mouse CD4 (CD4-FITC - cat. 115505, clone 6D5, LOT B131781, dilution 1:200), anti-mouse CD8a (CD8a-PE - cat. 101207, clone M1/70, LOT B166034, dilution 1:400), and anti-mouse CD62L (CD62L-APC - cat. 137607, clone 29A1.4, LOT B152186, dilution 1:200) and anti-mouse CD44(CD44-APC - cat. 137607, clone 29A1.4, LOT B152186, dilution 1:200) were purchased from BioLegend (BioLegend, London, UK). Antibody dilutions in cell staining buffer containing $1 \%$ TruStain fcX ${ }^{\mathrm{TM}}$ (anti-mouse CD16/32) Antibody 
(both BioLegend, London, UK) were used to stain according to the manufacturer's protocol. Antibody validation data is available from http://www.biolegend.com. Samples were acquired using a BD LSRII (Beckton Dickinson, Oxford, UK) and analysed using Flow Jo version 10.6.1 (Treestar, Ashland, OR, USA) software.

Immunohistochemistry: For detection of in vivo antibody deposition in cardiac tissue, $5 \mu \mathrm{m}$ sections of frozen post-ISOPROTERENOL hearts were stained with goat anti-mouse IgG-FITC (cat. F5387, Sigma-Aldrich, Dorset, UK), rat anti-mouse IgM-PE (cat. 406507, BioLegend, London, UK). Images were captured using a LMD7000 microscope (Leica microsystems, Milton Keynes, UK) processed using the public domain software Image $(\mathrm{NIH}$; http://rsb.info.nih.gov) (Schenider et al 2012)

Statistical analysis: Statistical analysis was performed using GraphPad Prism 8 and data were presented as mean \pm s.e.m throughout. Comparison between 2 groups was performed using student's t-test. Comparison between multiple experimental groups was performed using one- or two-way ANOVA with Dunnett's multiple comparisons post hoc test to obtain multiplicity-adjusted p-values. Non-parametric scoring data were analysed using KruskalWallis test with Dunn's multiple comparisons post hoc test to obtain multiplicity-adjusted pvalues. Differences were considered significant at $p<0.05$.

\section{Results:}

\section{(1) A single dose of $160 \mathrm{mg} / \mathrm{kg}$ isoproterenol induces significant cardiac damage in C57BL/6J}

mice. Different mouse strains show variable susceptibility to induction of cardiac damage and fibrosis, and $\mathrm{C} 57 \mathrm{BL} / 6 \mathrm{~J}$ mice have a very robust cardiac phenotype and are resistant to myocardial damage and cardiac fibrosis ${ }^{30}$. They are among the best characterised mouse strains and commonly used for genetic modification ${ }^{32}$. We therefore performed a dose titration experiment to investigate if $\mathrm{C} 57 \mathrm{BL} / 6 \mathrm{~J}$ mice were susceptible to developing cardiac lesions while maintaining high animal welfare standards. Mice were treated with a one-off bolus intra-peritoneal injection of increasing doses of isoproterenol starting with $40 \mathrm{mg} / \mathrm{kg}$ up to $320 \mathrm{mg} / \mathrm{kg}$. The highest dose of $320 \mathrm{mg} / \mathrm{kg}$ was administered as 2 separate $160 \mathrm{mg} / \mathrm{kg}$ doses on subsequent days. Isoproterenol effects were evident from 15 mins after injection, at which 
point mice ceased moving and increased respiration rates were observed. In general, mice recovered within 2 hours as judged by the return of normal feeding and grooming behaviour. $160 \mathrm{mg} / \mathrm{kg}$ isoproterenol induced significant increase in the cardiac damage biomarker cardiac Troponin I in the serum (Figure $1 \mathrm{~A}$ ) as well as myocardial infiltration and fibrosis 2 weeks after challenge (Figure 1B). Spleen/body ratio as a measure of systemic inflammation and body weight as indicator of overall health was not affected with doses up to $160 \mathrm{mg} / \mathrm{kg}$ (Figure 1C, D). $160 \mathrm{mg} / \mathrm{kg}$ each on 2 subsequent days however increased spleen/body ratio and reduced body weight. A single injection of $160 \mathrm{mg} / \mathrm{kg}$ was thus chosen as standard dose for subsequent experiments. Histopathologically, cardiac damage was accompanied by early patterns of necrosis followed by a maturing repair response resulting in granulation tissue and eventually fibrosis over an appropriate time-span of weeks. Consistent with catecholaminergic damage, and a strong component of ischemia, injury was most prominent in the subendocardium of the left ventricular free wall, but was essentially confluent and transmural in the septum (Figure 1E).

To further improve animal welfare benefits of the isoproterenol model, we included pretreatment with $0.05 \mathrm{mg} / \mathrm{kg}$ buprenorphine for pain relief. Buprenorphine was injected subcutaneously 30 minutes before isoproterenol administration. Manual mouse grimace scale (MGS) scoring was deemed not suitable, as no orbital tightening, or changes in nose and cheek bulge and whisker position was notable ${ }^{33}$. Instead, we measured activity (moving, feeding, drinking, grooming) as a reliable sign of both the onset of and the recovery from acute isoproterenol effects (Figure 2A). Adding buprenorphine to the isoproterenol treatment shortened the average time to recovery by 20 minutes without affecting the degree of cardiac inflammatory and fibrotic damage (Figure 2B).

(2) Kidney, liver, lung and skeletal muscle are protected from direct isoproterenol-induced damage. To define the degree of off-target damage to other organs, we performed a thorough histopathological assessment of kidneys, liver, lung and skeletal muscle at week 1 and 2 after injection of $160 \mathrm{mg} / \mathrm{kg}$ isoproterenol. Myocardial mononuclear infiltration and fibrosis was confirmed (Figure 3A). No pathological changes were observed in any of the other tested organs in any of the mice $(n=5)$ at week 1 (Figure 3B, C). At week 2, mild acute tubular injury and fibrosis was detectable in the kidneys (Figure 3B, C) which is likely secondary to cardiac damage as previously observed after surgical LAD ligation ${ }^{34}$. 
(3) CD4+ T cells in heart-draining mediastinal lymph nodes are activated in response to a single dose of $160 \mathrm{mg} / \mathrm{kg}$ isoproterenol. To investigate if the single high dose isoproterenol model was suitable for immunological readouts related to adaptive immune cell activation, we isolated heart-draining mediastinal lymph nodes for flow cytometry. 4 weeks after ISO injection, CD4+ helper T cells displayed an activated CD62L-CD44- effector cell phenotype (Figure 3).

(4) A single dose of $160 \mathrm{mg} / \mathrm{kg}$ isoproterenol triggers production of anti-heart autoantibodies. Activated autoreactive CD4+ helper T cells are able to induce B cells to generate autoantibodies, which are a hallmark sign of an established autoimmune response. We therefore tested week 2 (acute) and week 12 (chronic) post-isoproterenol serum for the presence of anti-heart autoantibodies. We found a significant increase of auto-antibody levels at chronic stage after isoproterenol damage (Figure 4A). Importantly, these were of the mature class-switched IgG isotype indicating an established and persistent adaptive immune response against the heart. We also found a significant amount of IgG as well as immature IgM deposited in the myocardium (Figure 4B, C) indicating in vivo deposition. The deposition pattern followed the myocardial fibres and the inside of blood vessels indicating the potential for endothelial and cardiomyocyte damage. 
Forte et al, Cardiac autoimmunity model

\section{Discussion:}

The definition of myocardial infarction differentiates patients with $\mathrm{MI}$ due to plaque rupture (T1MI) from those with myocardial necrosis due to oxygen supply-demand imbalance secondary to other acute illnesses (T2MI). Myocardial necrosis without symptoms or signs of myocardial ischaemia is classified as acute or chronic myocardial injury. Both myocardial injury and $\mathrm{T} 2 \mathrm{MI}$ are common, yet these patients have poor short-term and long-term outcomes ${ }^{35}$ with heart failure risk comparable to $\mathrm{T} 1 \mathrm{MI}^{36}$. Activation of the adaptive immune system and persistent autoimmunity against the heart have recently been suggested as pathological factors contributing to heart failure in response to $\mathrm{MI}^{37}{ }^{14}$. The number of corresponding experimental studies has surged and is anticipated to increase substantially in the near future as the cardiovascular community attempts to characterise the striking complexities of the post-MI immune response.

Here we show that a single dose of isoproterenol induces necrotic lesions in the heart. The initial trigger of necrotic cell death is most comparable to catecholamine-induced damage as seen during stress-related cardiomyopathies including takotsubo syndrome ${ }^{38} 39$ as well as in severely-ill patients receiving catecholamines for cardiac pacing or inotropic support ${ }^{40}$. High dose catecholamines also induce an imbalance between myocardial oxygen supply and demand, and the degree and pattern of inflammatory damage and replacement fibrosis is reminiscent of the myocardial damage incurred by a T2MI. Mild kidney fibrosis is also observed in isoproterenol-treated mice starting from week 2, which may be secondary to cardiac damage ${ }^{34}$ as not apparent at earlier timepoints. Other organs are not affected, which confirms that off-target tissue damage is not a limiting factor in this model.

Importantly, isoproterenol-induced myocardial necrosis releases antigenic peptides which induce $T$ cell activation in the heart-draining mediastinal lymph nodes. These activate $B$ cells to produce mature IgG anti-heart autoantibodies, a sign of a bona fide autoimmune response against the heart. Anti-heart auto-antibodies indicating autoimmunity has thus far been demonstrated in a wide range of human heart conditions ${ }^{41}$ and is likely due to high amounts of cardiac antigen in an inflammatory environment overwhelming immunological tolerance. Importantly, the adaptive immune system is activated by antigens released from necrotic cells irrespective of the initial cause of necrosis. Accordingly, we find anti-heart auto-antibodies in experimental models after surgical induction of MI via LAD ligation (Sintou et al. 2019) and under systemic inflammatory conditions ${ }^{28}$, as well as in the present study after chemical 
induction of myocardial necrosis. The common factor in these situations is myocardial necrosis, which is sufficient to induce a downstream adaptive immune response against the heart.

Rodents are routinely used for experimental MI studies and infarcts are commonly induced by ligation of the left anterior descending (LAD) artery during open chest surgery, an invasive procedure associated with high mortality rates. Despite widespread uptake, this model is not free from limitations, which include additional tissue damage and inflammation triggered by invasive thoracotomy, an excessive severity of experimental infarcts and the use of young, healthy mice which do not reflect the average MI patient demographic well (Table 1). In particular, T2MI and other cases of more subtle ischaemic cardiac tissue injury are not reflected well by surgical LAD ligation. In addition, the isoproterenol model is particularly useful for readouts including chronic and peripheral immunological measures, e.g. serum levels of cytokines and anti-heart autoantibodies, phenotype and function of immune cells in peripheral lymphoid organs, as well as effects of therapeutic approaches on these aspects. Table 1 summarises characteristics of surgical MI and isoproterenol models in comparison to the clinical situation in human MI patients. 
bioRxiv preprint doi: https://doi.org/10.1101/2020.02.27.962696; this version posted March 5,2020 . The copyright holder for this preprint (which was not certified by peer review) is the author/funder, who has granted bioRxiv a license to display the preprint in perpetuity. It is made available under aCC-BY 4.0 International license.

Forte et al, Cardiac autoimmunity model

\begin{tabular}{|c|c|c|c|c|}
\hline & $\begin{array}{c}\text { Human } \\
\text { myocardial infarction }\end{array}$ & $\begin{array}{c}\text { Isoproterenol } \\
\text { injection }\end{array}$ & $\begin{array}{l}\text { Permanent } \\
\text { LAD ligation }\end{array}$ & $\begin{array}{l}\text { Temporary } \\
\text { LAD ligation }\end{array}$ \\
\hline $\begin{array}{l}\text { Patient/subject } \\
\text { population }\end{array}$ & $\begin{array}{c}\text { Genetically diverse, } \\
\text { various co-morbidities }\end{array}$ & $\begin{array}{l}\text { Mostly inbred, healthy, } \\
\text { young animals } 43 \\
\text { (experimental co- } \\
\text { morbidities possible due } \\
\text { to mild ISO challenge) }\end{array}$ & \multicolumn{2}{|c|}{$\begin{array}{l}\text { Mostly inbred, healthy, young animals } 43 \\
\text { (experimental co-morbidities difficult as surgical } \\
\text { challenge is already severe) }\end{array}$} \\
\hline Cause of damage & $\begin{array}{c}\text { Mixed population; } \\
\text { temporary or permanent } \\
\text { oxygen deprivation and/or } \\
\text { I/R injury }{ }^{2}\end{array}$ & $\begin{array}{l}\text { Overstimulation of } ß- \\
\text { adrenergic receptors } \\
\text { inducing oxygen } \\
\text { deprivation } 1617\end{array}$ & $\begin{array}{l}\text { Permanent block of } \\
\text { blood supply, } \\
\text { surgical damage to } \\
\text { thoracic cavity and } \\
\text { pericardium } 4445\end{array}$ & $\begin{array}{c}\text { Temporary block of } \\
\text { blood supply - I/R injury, } \\
\text { surgical damage to } \\
\text { thoracic cavity and } \\
\text { pericardium } 4546\end{array}$ \\
\hline $\begin{array}{l}\text { Early innate } \\
\text { immune stimulus }\end{array}$ & $\begin{array}{l}\text { tissue necrosis with/without } \\
\text { complement activation } 4748\end{array}$ & \multicolumn{2}{|c|}{ tissue necrosis 161744} & $\begin{array}{c}\text { tissue necrosis and } \\
\text { complement activation }^{49}\end{array}$ \\
\hline Severity & $\begin{array}{l}\text { Varying severity, rarely } \\
\text { transmural, mostly regional, } \\
\text { sub-endocardial, micro- } \\
\text { infarcts } 5051\end{array}$ & $\begin{array}{l}\text { Diffuse patchy damage, } \\
\text { primarily in endocardium } \\
16\end{array}$ & $\begin{array}{l}\text { severe trans-mural } \\
\text { infarcts in LV (mimics } \\
\text { severe T1MI without } \\
\text { reperfusion } \sim 25 \% \text { of } \\
\text { patients) } 5253\end{array}$ & $\begin{array}{l}\text { Severe, often trans- } \\
\text { mural infarcts in LV } \\
\text { (mimics severe T1MI } \\
\text { with reperfusion) }{ }^{54}\end{array}$ \\
\hline Scarring & $\begin{array}{l}\text { Varying degree of scarring } \\
\text { depending on initial degree } \\
\text { of damage } 55\end{array}$ & $\begin{array}{l}\text { Patches of fibrotic/scar } \\
\text { tissue resembling T2MI } \\
\text { or micro-infarcts }{ }^{16}\end{array}$ & \multicolumn{2}{|c|}{$\begin{array}{l}\text { majority of LV wall replaced by full thickness scar, } \\
\text { additional scarring and damage due to MI surgery } \\
{ }_{45}^{53}\end{array}$} \\
\hline $\begin{array}{l}\text { Functional and } \\
\text { morphological } \\
\text { response }\end{array}$ & $\begin{array}{l}\text { Remodelling and functional } \\
\text { decline to heart failure }{ }^{6}\end{array}$ & $\begin{array}{l}\text { Mild effects on } \\
\text { remodelling and dilation, } \\
\text { mild functional decline } \\
305657\end{array}$ & $\begin{array}{l}\text { strong remodelling } \\
\text { response, dilation and } \\
\text { progression to heart } \\
\text { failure } 5859\end{array}$ & $\begin{array}{l}\text { moderate remodelling } \\
\text { response, dilation and } \\
\text { progression to heart } \\
\text { failure } 5445\end{array}$ \\
\hline $\begin{array}{l}\text { Adaptive immune } \\
\text { stimulus }\end{array}$ & $\begin{array}{l}\text { Cardiac antigen (e.g. myosin, } \\
\text { troponin) in circulation } 6061\end{array}$ & \multicolumn{3}{|c|}{ Cardiac antigen (e.g. myosin, troponin) in circulation 6263} \\
\hline $\begin{array}{l}\text { Adaptive immune } \\
\text { response }\end{array}$ & $\begin{array}{c}\text { Long-term auto-reactivity, } \\
\text { anti-heart auto-antibodies } 64\end{array}$ & \multicolumn{2}{|c|}{ anti-heart auto-antibodies ${ }^{14}$} & $\begin{array}{l}\text { Anticipated: anti-heart } \\
\text { auto-antibodies }\end{array}$ \\
\hline
\end{tabular}

Importantly, besides resource efficiency, replacing surgical MI procedures carries significant animal welfare benefits. Isoproterenol injections cause transient effects and are significantly less invasive than MI surgeries. In our hands, isoproterenol treatment carries an approximate mortality of $1 \%$ mostly due to acute arrhythmias in the first $24-48 \mathrm{~h}$ after injection. Visible effects of appropriately titrated isoproterenol injections wear off within 1-2 hours after injection. Several opportunities to reduce necessary animal numbers also arise through the use of isoproterenol as alternative to LAD ligation surgery. Invasive thoracotomy causes a significant amount of tissue damage and inflammation and risks flawed interpretation of immunological readouts. Thus, there is scientific need for sham operated animals, while simple PBS injected controls are suitable for isoproterenol experiments. Isoproterenol is administered by intra-peritoneal injection, a simple technique that can be learned easily, avoiding increased mortality rates due to inexperienced researchers. Isoproterenol effects are also more homogenous between treated animals than surgical infarcts, allowing 
bioRxiv preprint doi: https://doi.org/10.1101/2020.02.27.962696; this version posted March 5, 2020. The copyright holder for this preprint (which was not certified by peer review) is the author/funder, who has granted bioRxiv a license to display the preprint in perpetuity. It is made available under aCC-BY 4.0 International license.

Forte et al, Cardiac autoimmunity model

significant reduction of group sizes. Susceptibility to isoproterenol-induced damage varies between mouse strains. However, after appropriate dose studies, isoproterenol can be used in both sexes of all mouse strains, avoiding surplus animals and allowing the use of transgenic mice on their respective background.

In summary, a single high-dose isoproterenol injection is a suitable method to induce adaptive immune responses against the myocardium with significant additional resource and animal welfare benefits. 
Forte et al, Cardiac autoimmunity model

\section{References:}

1. Michaud, K. et al. Diagnosis of myocardial infarction at autopsy: AECVP reappraisal in the light of the current clinical classification. Virchows Arch. 476, 179-194 (2020).

2. Thygesen, K. et al. Fourth universal definition of myocardial infarction (2018). Eur. Heart J. 40, 237-269 (2019).

3. Sandoval, Y. \& Jaffe, A. S. Type 2 Myocardial Infarction. J. Am. Coll. Cardiol. 73, 18461860 (2019).

4. Gupta, S., Vaidya, S. R., Arora, S., Bahekar, A. \& Devarapally, S. R. Type 2 versus type 1 myocardial infarction: a comparison of clinical characteristics and outcomes with a meta-analysis of observational studies. Cardiovasc. Diagn. Ther. 7, 348-358 (2017).

5. Defilippis, A. P. et al. Assessment and Treatment of Patients With Type 2 Myocardial Infarction and Acute Nonischemic Myocardial Injury. Circulation 140, 1661-1678 (2019).

6. Torabi, A. et al. The timing of development and subsequent clinical course of heart failure after a myocardial infarction. Eur. Heart J. 29, 859-870 (2008).

7. Adamo, L., Rocha-Resende, C., Prabhu, S. D. \& Mann, D. L. Reappraising the role of inflammation in heart failure. Nat. Rev. Cardiol. (2020) doi:10.1038/s41569-019-0315$\mathrm{x}$.

8. Dick, S. A. \& Epelman, S. Chronic Heart Failure and Inflammation. Circ. Res. 119, 159176 (2016).

9. Martini, E. et al. Single-Cell Sequencing of Mouse Heart Immune Infiltrate in Pressure Overload-Driven Heart Failure Reveals Extent of Immune Activation. Circulation (2019) doi:10.1161/CIRCULATIONAHA.119.041694.

10. Strassheim, D., Dempsey, E. C., Gerasimovskaya, E., Stenmark, K. \& Karoor, V. Role of inflammatory cell subtypes in heart failure. Journal of Immunology Research (2019) doi:10.1155/2019/2164017.

11. Düngen, H.-D. et al. $\beta 1$-Adrenoreceptor Autoantibodies in Heart Failure. Circ. Hear. Fail. 13, (2020).

12. Kallikourdis, M. et al. T cell costimulation blockade blunts pressure overload-induced heart failure. Nat. Commun. 8, 14680 (2017).

13. Sattler, S., Fairchild, P., Watt, F. M., Rosenthal, N. \& Harding, S. E. The adaptive immune response to cardiac injury - the true roadblock to effective regenerative therapies? npj Regen. Med. 2, 19 (2017).

14. Sintou, A. et al. Persistent anti-heart autoimmunity causes cardiomyocyte damage in chronic heart failure. https//www. biorxiv.org/content/10.1101/542597v1?rss=1, undergoing peer Rev. Nat. Commun.

15. Lindsey, M. L. et al. Guidelines for experimental models of myocardial ischemia and infarction. Am. J. Physiol. - Hear. Circ. Physiol. 314, H812-H838 (2018).

16. RONA, G., CHAPPEL, C. I., BALAZS, T. \& GAUDRY, R. An infarct-like myocardial lesion and other toxic manifestations produced by isoproterenol in the rat. AMA. Arch. Pathol. 67, 443-55 (1959).

17. Kung, H. F. \& Blau, M. Subcutaneous isoproterenol: A convenient rat model for early detection of myocardial necrosis. J. Nucl. Med. (1978).

18. Benjamin, I. J. et al. Isoproterenol-induced myocardial fibrosis in relation to myocyte necrosis. Circ. Res. 65, 657-670 (1989).

19. Stanton, H. C. \& Bowman, Z. Studies on isoproterenol-induced cardiomegaly in rats. Proc. West. Pharmacol. Soc. (1967). 
20. Ennis, I. L. et al. Regression of Isoproterenol-Induced Cardiac Hypertrophy by $\mathrm{Na}+/ \mathrm{H}$ + Exchanger Inhibition. Hypertension 41, 1324-1329 (2003).

21. Chang, S. C., Ren, S., Rau, C. D. \& Wang, J. J. Isoproterenol-Induced Heart Failure Mouse Model Using Osmotic Pump Implantation. in Methods in Molecular Biology 207-220 (2018). doi:10.1007/978-1-4939-8597-5_16.

22. Králová, E., Mokrán, T., Murín, J. \& Stankovicová, T. Electrocardiography in two models of isoproterenol-induced left ventricular remodeling. Physiol. Res. 57 Suppl 2, S83-9 (2008).

23. Ellison, G. M. et al. Adult c-kitpos Cardiac Stem Cells Are Necessary and Sufficient for Functional Cardiac Regeneration and Repair. Cell 154, 827-842 (2013).

24. Ellison, G. M. et al. Acute $\beta$-Adrenergic Overload Produces Myocyte Damage through Calcium Leakage from the Ryanodine Receptor 2 but Spares Cardiac Stem Cells. J. Biol. Chem. 282, 11397-11409 (2007).

25. Overgaard, C. B. \& Džavík, V. Inotropes and Vasopressors. Circulation 118, 1047-1056 (2008).

26. Lorell, B. H., Isoyama, S., Grice, W. N., Weinberg, E. O. \& Apstein, C. S. Effects of ouabain and isoproterenol on left ventricular diastolic function during low-flow ischemia in isolated, blood-perfused rabbit hearts. Circ. Res. 63, 457-467 (1988).

27. Farmakis, D. et al. A pragmatic approach to the use of inotropes for the management of acute and advanced heart failure: An expert panel consensus. Int. J. Cardiol. (2019) doi:10.1016/j.ijcard.2019.09.005.

28. Hasham, M. G. et al. Systemic autoimmunity induced by the TLR7/8 agonist Resiquimod causes myocarditis and dilated cardiomyopathy in a new mouse model of autoimmune heart disease. Dis. Model. Mech. 10, 259-270 (2017).

29. Schneider, C. A., Rasband, W. S. \& Eliceiri, K. W. NIH Image to ImageJ: 25 years of image analysis. Nat. Methods 9, 671-675 (2012).

30. Wang, J., Huertas-Vazquez, A., Wang, Y. \& Lusis, A. J. Isoproterenol-Induced Cardiac Diastolic Dysfunction in Mice: A Systems Genetics Analysis. Front. Cardiovasc. Med. 6, (2019).

31. Walkin, L. et al. The role of mouse strain differences in the susceptibility to fibrosis: a systematic review. Fibrogenesis Tissue Repair 6, 18 (2013).

32. Barnabei, M. S., Palpant, N. J. \& Metzger, J. M. Influence of genetic background on ex vivo and in vivo cardiac function in several commonly used inbred mouse strains. Physiol. Genomics 42A, 103-113 (2010).

33. Langford, D. J. et al. Coding of facial expressions of pain in the laboratory mouse. Nat. Methods 7, 447-449 (2010).

34. Ranganathan, P. et al. MicroRNA-150 deletion in mice protects kidney from myocardial infarction-induced acute kidney injury. Am. J. Physiol. Physiol. 309, F551F558 (2015).

35. Chapman, A. R., Adamson, P. D. \& Mills, N. L. Assessment and classification of patients with myocardial injury and infarction in clinical practice. Heart 103, 10-18 (2017).

36. Chapman, A. R. et al. Long-Term Outcomes in Patients With Type 2 Myocardial Infarction and Myocardial Injury. Circulation 137, 1236-1245 (2018).

37. Sattler, S., Fairchild, P., Watt, F. M., Rosenthal, N. \& Harding, S. E. The adaptive immune response to cardiac injury - the true roadblock to effective regenerative therapies? npj Regen. Med. 2, 19 (2017). 
38. Paur, H. et al. High Levels of Circulating Epinephrine Trigger Apical Cardiodepression in a $\beta 2$-Adrenergic Receptor/G i-Dependent Manner. Circulation 126, 697-706 (2012).

39. Sattler, S., Couch, L. S. \& Harding, S. E. Takotsubo Syndrome. JACC Basic to Transl. Sci. 3, 779-781 (2018).

40. Haft, J. I. Cardiovascular injury induced by sympathetic catecholamines. Prog. Cardiovasc. Dis. 17, 73-86 (1974).

41. Kaya, Z., Leib, C. \& Katus, H. A. Autoantibodies in Heart Failure and Cardiac Dysfunction. Circ. Res. 110, 145-158 (2012).

42. Petrie, J. R., Guzik, T. J. \& Touyz, R. M. Diabetes, Hypertension, and Cardiovascular Disease: Clinical Insights and Vascular Mechanisms. Can. J. Cardiol. 34, 575-584 (2018).

43. Perlman, R. L. Mouse Models of Human Disease: An Evolutionary Perspective. Evol. Med. Public Heal. eow014 (2016) doi:10.1093/emph/eow014.

44. Kolk, M. V. V. et al. LAD-Ligation: A Murine Model of Myocardial Infarction. J. Vis. Exp. (2009) doi:10.3791/1438.

45. Riehle, C. \& Bauersachs, J. Small animal models of heart failure. Cardiovasc. Res. 115, 1838-1849 (2019).

46. Michael, L. H. et al. Myocardial ischemia and reperfusion: A murine model. Am. J. Physiol. - Hear. Circ. Physiol. (1995) doi:10.1152/ajpheart.1995.269.6.h2147.

47. Zhang, W. et al. Necrotic myocardial cells release Damage-Associated Molecular Patterns that provoke fibroblast activation in vitro and trigger myocardial inflammation and fibrosis in vivo. J. Am. Heart Assoc. (2015) doi:10.1161/JAHA.115.001993.

48. Frangogiannis, N. G. The inflammatory response in myocardial injury, repair, and remodelling. Nature Reviews Cardiology (2014) doi:10.1038/nrcardio.2014.28.

49. Sharif-Paghaleh, E. et al. Non-Invasive whole-body detection of complement activation using radionuclide imaging in a mouse model of myocardial ischaemiareperfusion injury. Sci. Rep. 7, 16090 (2017).

50. Padfield, G. J. et al. Cardiovascular effects of tumour necrosis factor $\alpha$ antagonism in patients with acute myocardial infarction: a first in human study. Heart 99, 13301335 (2013).

51. Algranati, D., Kassab, G. S. \& Lanir, Y. Why is the subendocardium more vulnerable to ischemia? A new paradigm. Am. J. Physiol. - Hear. Circ. Physiol. (2011) doi:10.1152/ajpheart.00473.2010.

52. Puricel, S. et al. Clinical outcomes after PCl for acute coronary syndrome in unprotected left main coronary artery disease: insights from the Swiss Acute Left Main Coronary Vessel Percutaneous Management (SALVage) study. Eurolntervention 7, 697-704 (2011).

53. Virag, J. A. I. \& Lust, R. M. Coronary Artery Ligation and Intramyocardial Injection in a Murine Model of Infarction. J. Vis. Exp. (2011) doi:10.3791/2581.

54. Xu, Z., Alloush, J., Beck, E. \& Weisleder, N. A Murine Model of Myocardial Ischemiareperfusion Injury through Ligation of the Left Anterior Descending Artery. J. Vis. Exp. (2014) doi:10.3791/51329.

55. Richardson, W. J., Clarke, S. A., Quinn, T. A. \& Holmes, J. W. Physiological Implications of Myocardial Scar Structure. in Comprehensive Physiology 1877-1909 (John Wiley \& Sons, Inc., 2015). doi:10.1002/cphy.c140067. 
56. Teerlink, J. R., Pfeffer, J. M. \& Pfeffer, M. A. Progressive ventricular remodeling in response to diffuse isoproterenol- induced myocardial necrosis in rats. Circ. Res. (1994) doi:10.1161/01.res.75.1.105.

57. Brooks, W. W. \& Conrad, C. H. Isoproterenol-induced myocardial injury and diastolic dysfunction in mice: structural and functional correlates. Comp. Med. 59, 339-43 (2009).

58. Muthuramu, I., Lox, M., Jacobs, F. \& De Geest, B. Permanent Ligation of the Left Anterior Descending Coronary Artery in Mice: A Model of Post-myocardial Infarction Remodelling and Heart Failure. J. Vis. Exp. (2014) doi:10.3791/52206.

59. Pfeffer, M. A. et al. Myocardial infarct size and ventricular function in rats. Circ. Res. 44, 503-512 (1979).

60. Park, K. C., Gaze, D. C., Collinson, P. O. \& Marber, M. S. Cardiac troponins: from myocardial infarction to chronic disease. Cardiovasc. Res. 113, 1708-1718 (2017).

61. Katus, H. A. et al. Diagnosis of acute myocardial infarction by detection of circulating cardiac myosin light chains. Am. J. Cardiol. 54, 964-970 (1984).

62. Göser, S. et al. Cardiac Troponin I but Not Cardiac Troponin T Induces Severe Autoimmune Inflammation in the Myocardium. Circulation 114, 1693-1702 (2006).

63. Frobert, A. et al. Prognostic value of troponin I for infarct size to improve preclinical myocardial infarction small animal models. Front. Physiol. (2015) doi:10.3389/fphys.2015.00353.

64. Vilela, E. M. et al. Anti-cardiac troponin antibodies in clinical human disease: a systematic review. Ann. Transl. Med. 5, 307-307 (2017). 


\section{Figure legends:}

Figure 1: A one-off high dose of isoproterenol induces myocardial inflammation and fibrosis in C57BI/6JJ mice. C57BL/6J mice were treated with a single increasing one-off dose of isoproterenol to induce myocardial ischemia and cardiomyocyte necrosis and analysed 2 weeks after challenge. (A) Serum cardiac troponin I levels to confirm myocardial injury. (B) Infiltration and fibrosis were scored on a scale from 0 to 3 (none, mild, moderate, severe) in 4 fields of view in 2 heart cross-sections at mid-level per mouse. (C) Splenomegaly (spleen/body weight ratio) as a measure of systemic immune activation. (D) Change in body weight. (E) Micrographs of H\&E- and Picrosirius Red-stained paraffin-embedded cross sections of the hearts showing mononuclear cell infiltration (H\&E) and interstitial fibrosis (Picrosirius Red). n=3/group. Data are expressed as mean +/- s.e.m., ${ }^{*} p<0.05,{ }^{* *} p<0.001$, ***p $<0.0001$ (B: non-parametric Kruskal-Wallis with Dunn's multiple comparisons post hoc test comparing each time point to baseline $(A, C, D)$ one-way ANOVA with Dunnett's multiple comparisons post hoc test comparing each time point to baseline).

Figure 2: Addition of $0.05 \mathrm{mg} / \mathrm{kg}$ buprenorphine further decreases procedural severity as measured by activity scoring without affecting infiltration and fibrosis scores. C57BL/6J mice were treated with a single $160 \mathrm{mg} / \mathrm{kg}$ dose of isoproterenol with and without $0.05 \mathrm{mg} / \mathrm{kg}$ buprenorphine to induce myocardial ischemia and cardiomyocyte necrosis under analgesia. (A) Count of animals with normal movement and activity. (B) Average time until recovery of normal activity pattern. (C) Infiltration and fibrosis in cardiac tissue sections were scored on a scale from 0 to 3 (none, mild, moderate, severe) in 4 fields of view in 2 heart cross-sections at mid-level per mouse. $n=3 /$ group. Histopathology scoring data are expressed as mean $+/$ s.e.m., ${ }^{*} p<0.05$ (non-parametric Kruskal-Wallis with Dunn's multiple comparisons post hoc test comparing each time point to baseline).

Figure 3: A single high dose of isoproterenol does not affect liver, lung and skeletal muscle, but pathological changes in the kidneys are observed secondary to cardiac damage at week

2. $\mathrm{C} 57 \mathrm{BL} / 6 \mathrm{~J}$ mice were treated with a single one-off dose of isoproterenol to induce myocardial ischemia and cardiomyocyte necrosis. (A) Myocardial infiltration and fibrosis were scored on a scale from 0 to 3 (none, mild, moderate, severe) in 4 fields of view in 2 heart 
cross-sections at mid-level per mouse. (B) Kidney fibrosis was scored on a scale from 0 to 3 (none, mild, moderate, severe) in 4 fields of view in 2 cross-sections per mouse. $n=5 /$ group. Data are expressed as mean +/- s.e.m., ${ }^{*} p<0.05$ (non-parametric Kruskal-Wallis with Dunn's multiple comparisons post hoc test comparing each time point to baseline). (C) Micrographs of H\&E- and Picrosirius Red-stained paraffin-embedded sections of post-isoproterenol organs for assessment of mononuclear cell infiltration (H\&E) and interstitial fibrosis (Picrosirius Red). Representative image shown.

Figure 4: CD4+ T cells in heart-draining mediastinal lymph nodes are activated in response to A single dose of $160 \mathrm{mg} / \mathrm{kg}$ isoproterenol. $\mathrm{C} 57 \mathrm{BL} / 6 \mathrm{~J}$ mice were treated with a single oneoff dose of isoproterenol to induce myocardial ischemia and cardiomyocyte necrosis and flow cytometry was performed on a single cell preparation of the mediastinal lymph nodes. (A) Gating strategy to obtain the $\mathrm{CD} 3+\mathrm{T}$ cell population among $\mathrm{CD} 45+$ leukocytes. (B) Representative contour plots of CD62L and CD44 staining of CD3+CD4+ T cells and corresponding quantification of the DCD62 $\mathrm{L}^{-} \mathrm{CD} 44^{-}$subpopulation of effector $\mathrm{T}$ cells of Isoproterenol-treated versus control mice. $n=5-6 /$ group. Data are expressed as mean +/s.e.m., ${ }^{*} \mathrm{p}<0.05$ (Student's t test).

Figure 5: A single dose of $160 \mathrm{mg} / \mathrm{kg}$ isoproterenol triggers production of anti-heart autoantibodies. C57BL/6J mice were treated with a single one-off dose of $160 \mathrm{mg} / \mathrm{kg}$ isoproterenol to induce myocardial ischemia and cardiomyocyte necrosis and the heart and serum were obtained for analysis of anti-heart autoantibody production. (A) Levels of anti-cardiac autoantibodies in the serum over time as tested by ELISA using serum of ISOPROTERENOL-treated mice against rat cardiac lysate. (B, C) Quantification of $\mathrm{MFI}(\mathrm{B})$ and representative Immunofluorescence staining (C) of frozen heart sections of isoproterenol-treated mice 4 weeks after challenge, using goat anti-mouse IgG-FITC and rat anti-mouse IgM-PE to detect in vivo deposits of anti-heart auto-antibodies, green: IgG, red: IgM, blue: DAPI staining nuclei. $\mathrm{n}=5-6 /$ group. Data are expressed as mean +/- s.e.m., ${ }^{* *} \mathrm{p}<0.001$ (one-way ANOVA with Dunnett's multiple comparisons post hoc test comparing each time point to baseline).

Acknowledgements: We would like to thank staff at the animal facility at Imperial College London and The Jackson Laboratories for help with animal husbandry and maintenance. The 
authors also acknowledge the support by the Imperial College Facility for Imaging and Light Microscopy (FILM) and the LMS/NIHR Imperial Biomedical Research Centre Flow Cytometry. We gratefully acknowledge the contribution of Dr David Coleman and the Pathology Services Service at The Jackson Laboratory for expert assistance with the work described in this publication.

Sources of Funding: This work was supported by the British Heart Foundation (PG/16/93/32345 to SS), ISSF Welcome Trust 'Value in People Award' [105603/Z/14/Z to S.S.], the Medical Research Council (via King's College London) UKRMP Immunomodulation Hub [MR/L022699/1 to S.E.H.] and the Leducq Foundation: Trans-Atlantic Networks of Excellence in Cardiovascular Research and The Jackson Laboratory endowment to NR [TJL-Rosenthal-01 to N.R.].

\section{Competing interests}

The authors declare no competing financial interests.

\section{Author contributions}

E.F., M.G.H. and S.S. planned, designed, performed and analysed experiments. M.P., O.B. and J.Branca performed and analysed experiments. S.S. and F.S.N wrote the manuscript. J.Boyle and F.S.N. provided expert advice on histopathology and clinical cardiology and revised the manuscript. S.E.H., N.R. and S.S. provided supervision and financial support 


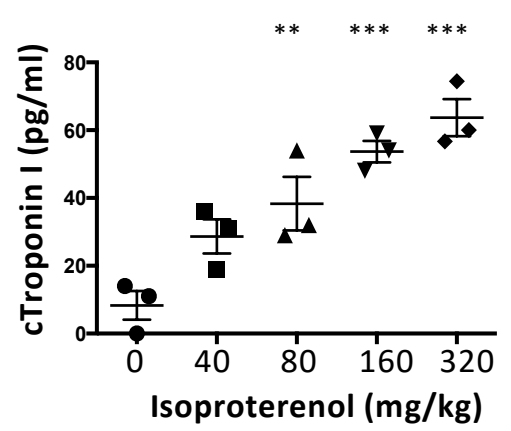

C

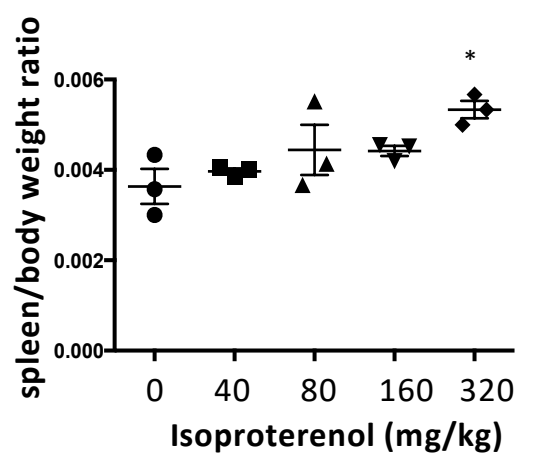

E

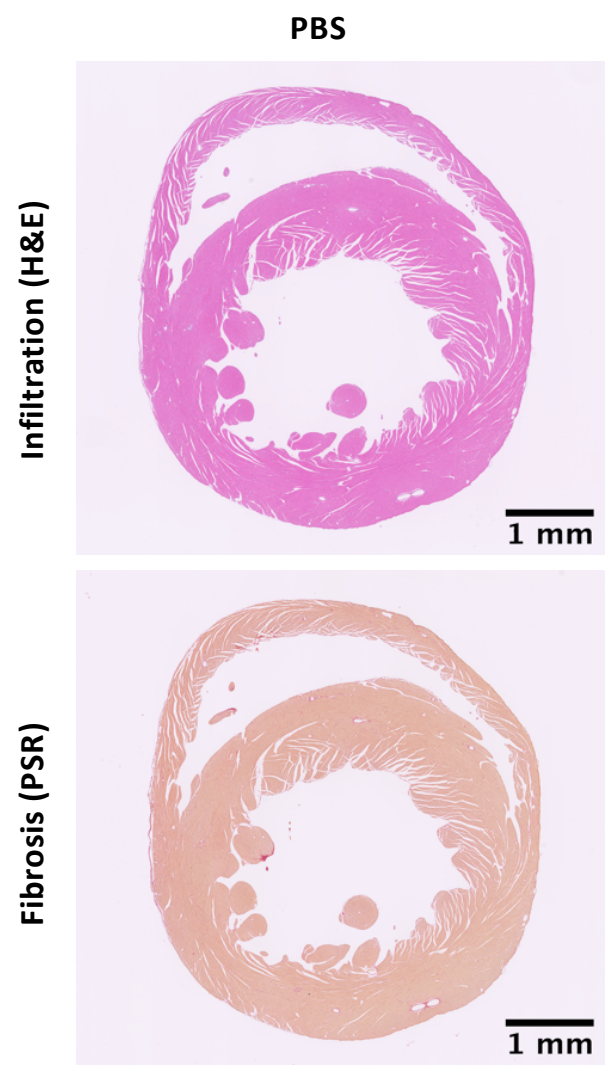

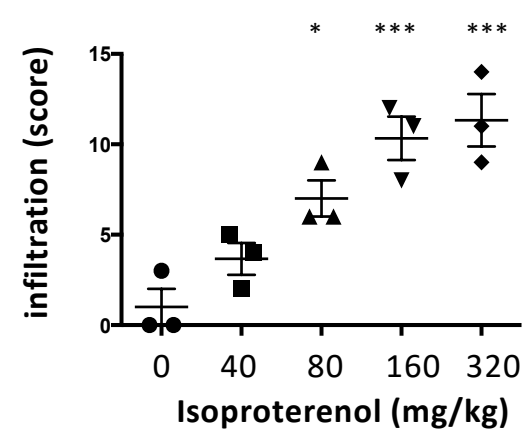

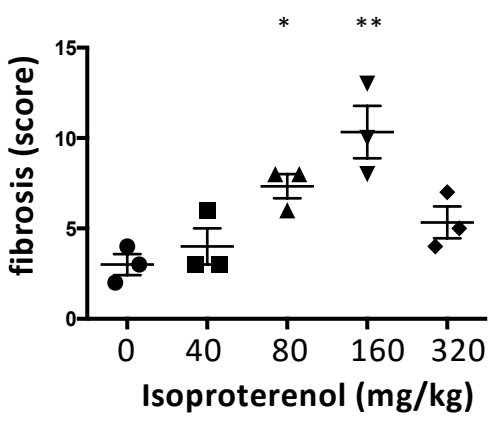

D

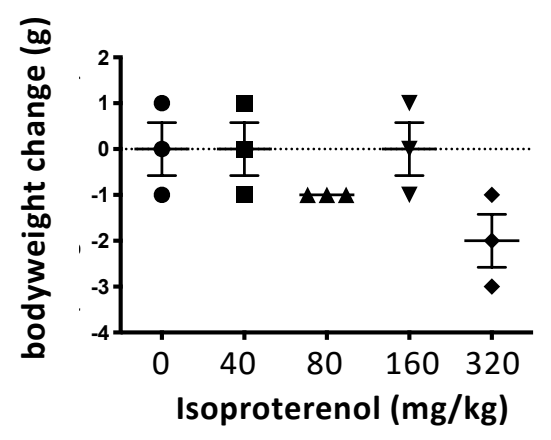

Isoproterenol
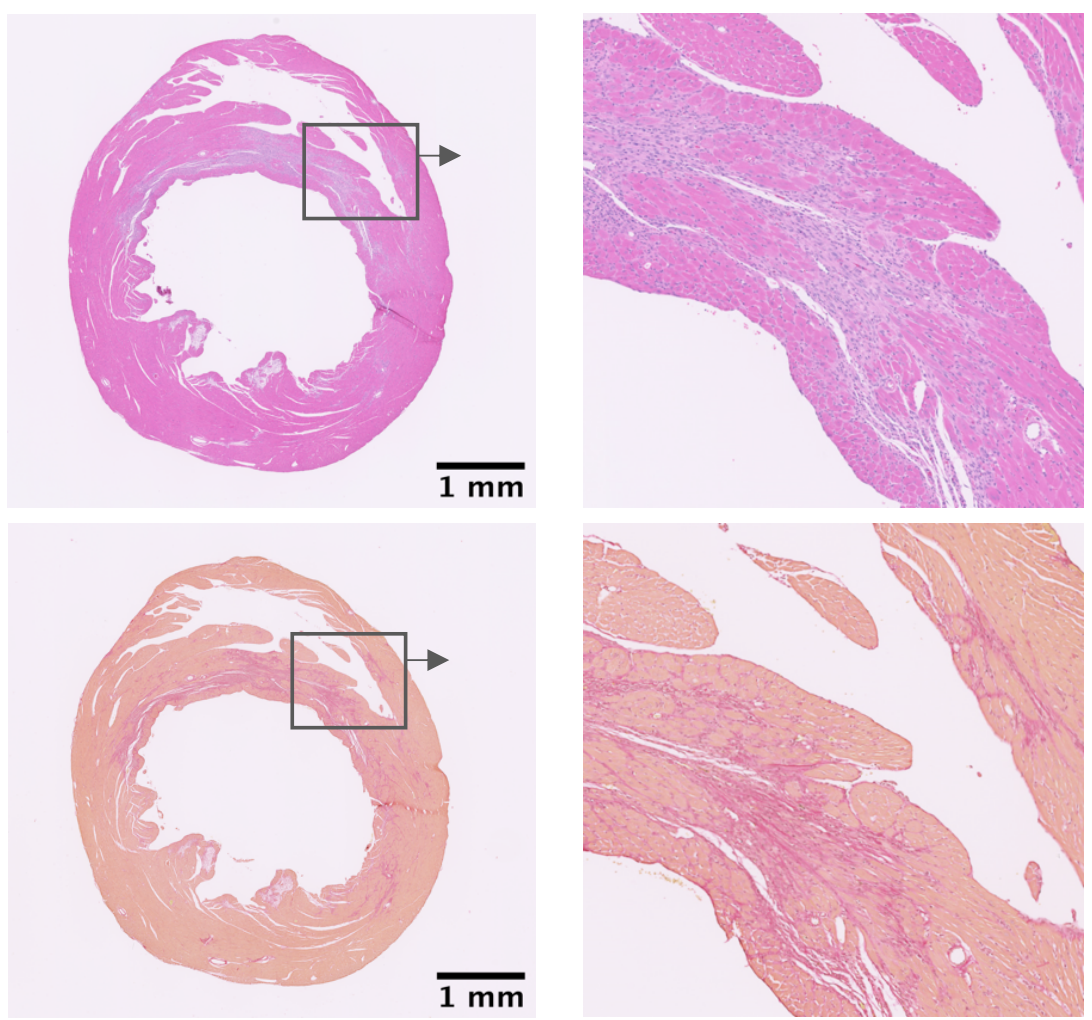

made available under aCC-BY 4.0 International license.

A

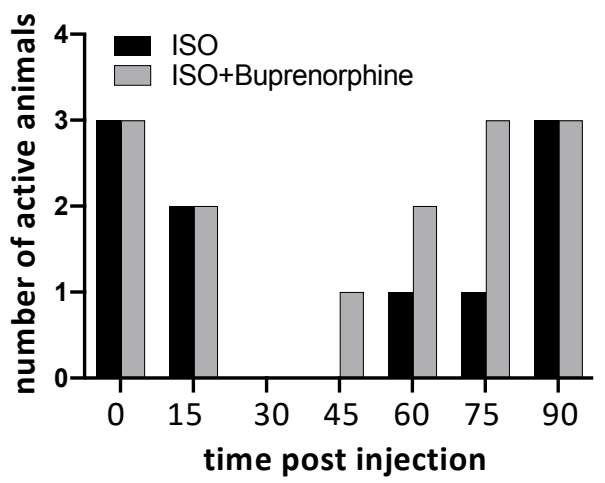

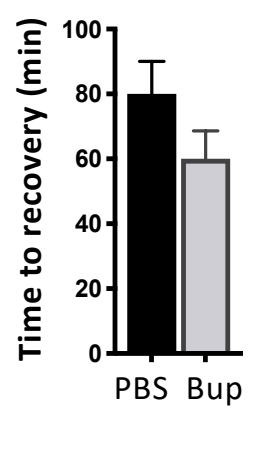

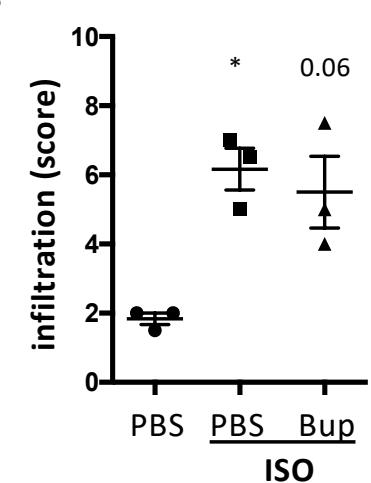


A B
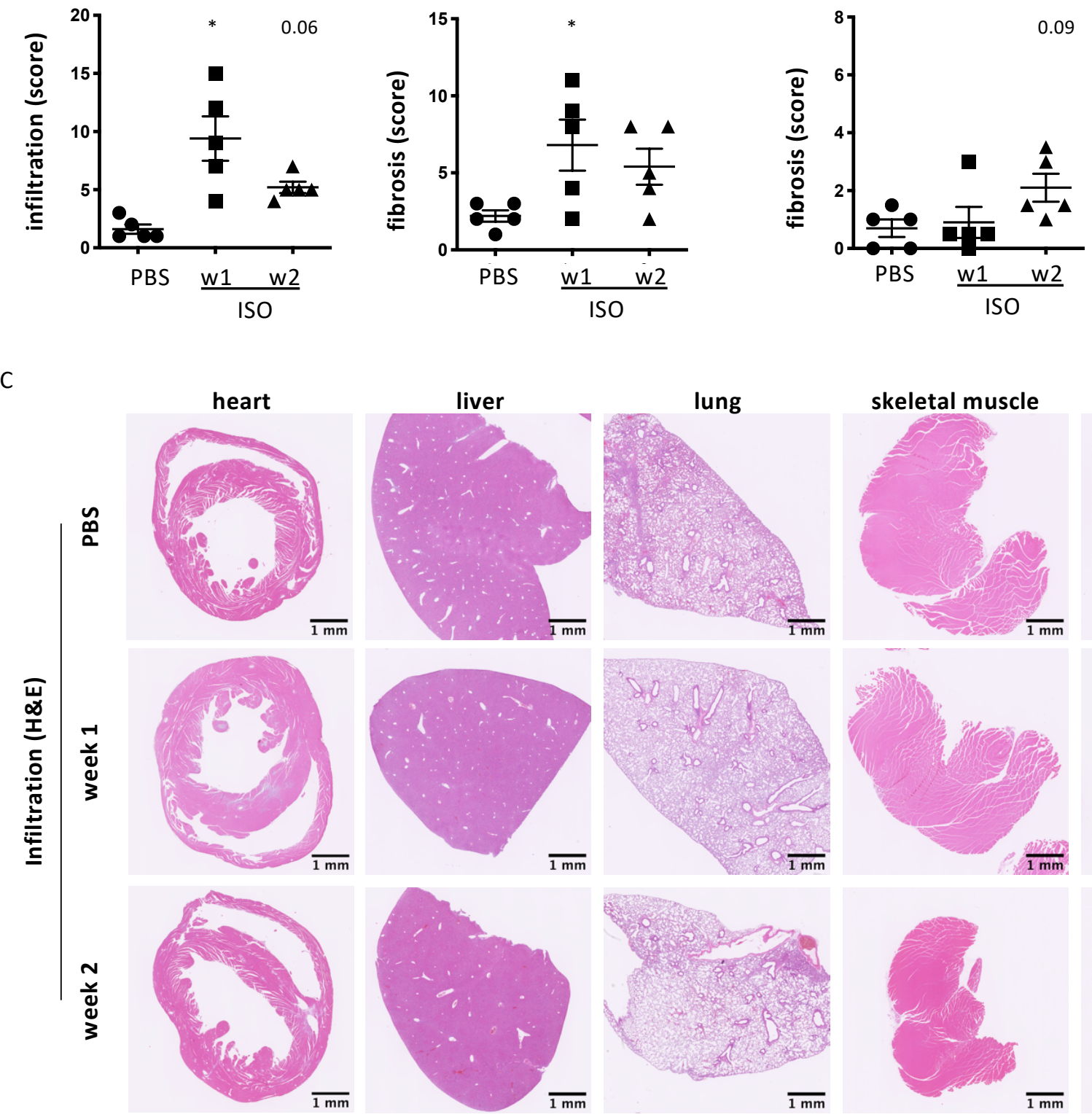

kidney
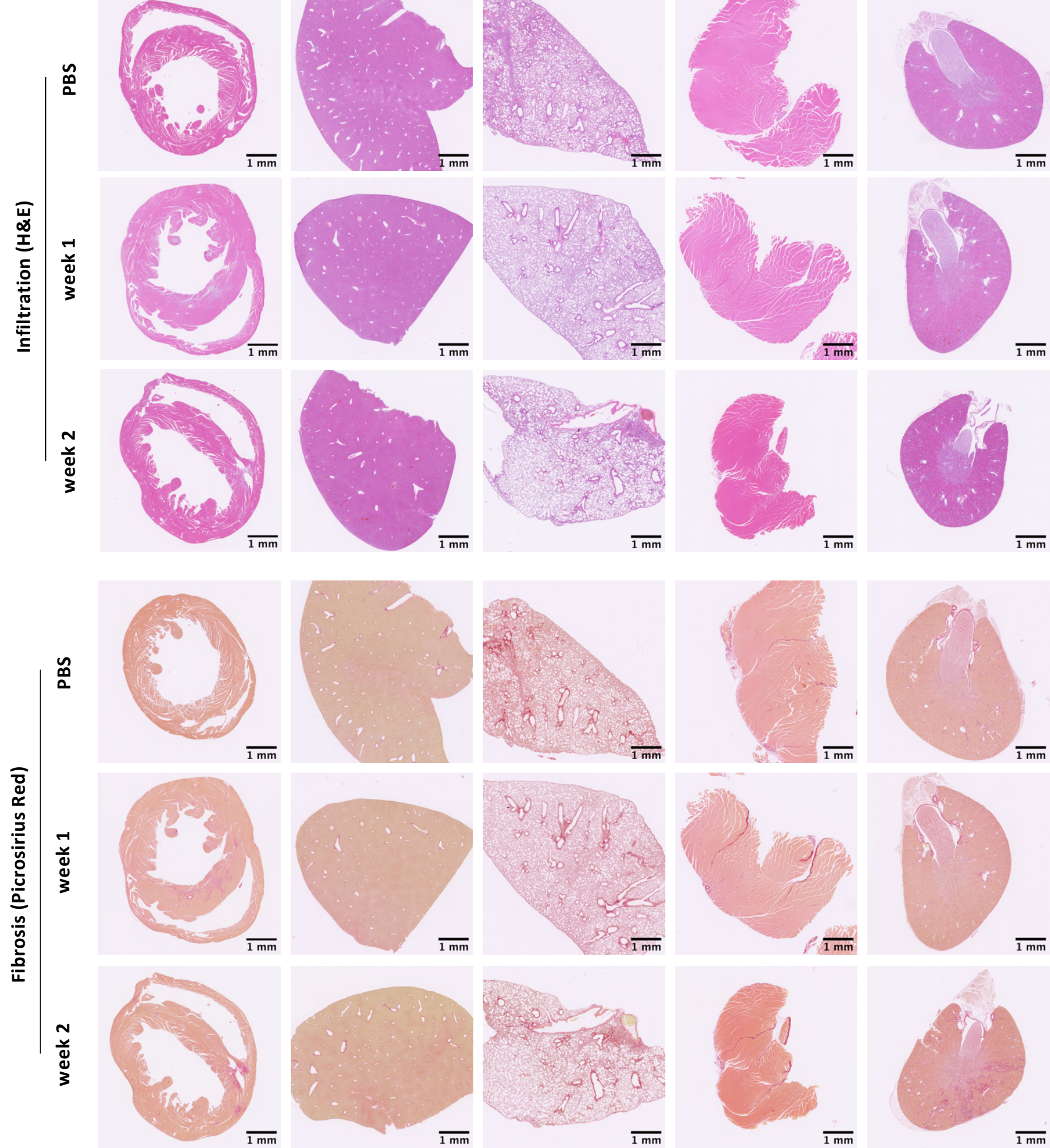
bioRxiv preprint doi: https://doi.org/10.1101/2020.02.27.962696; this version posted March 5 , 2020. The copyright holder for this preprint

(which was not certified by peer review) is the author/funder, who has granted bioRxiv a license to display the preprint in perpetuity. It is Figure $4^{\text {(which was not certified by peer review) }}$ made available under aCC-BY 4.0 International license.

A
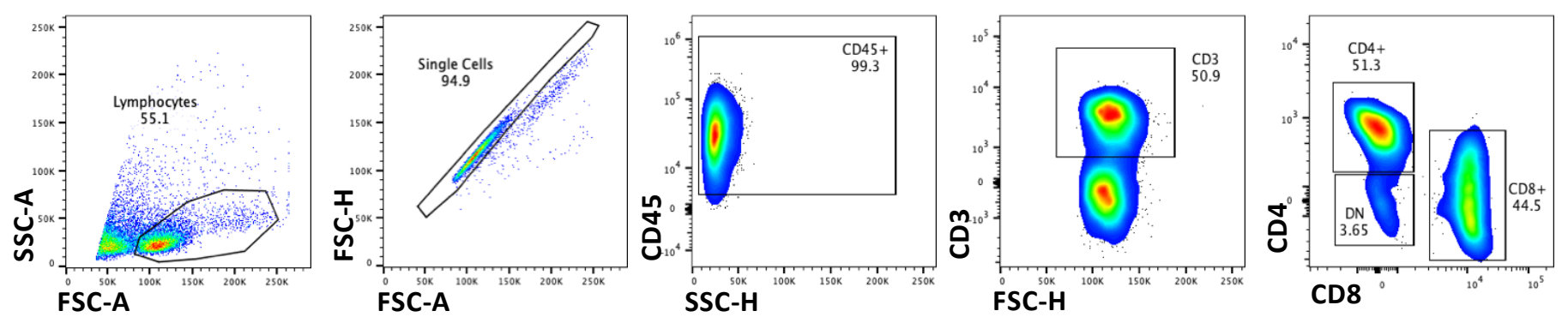

B

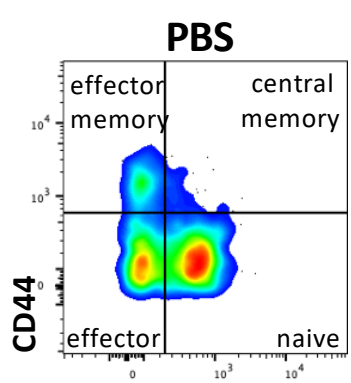

CD62L

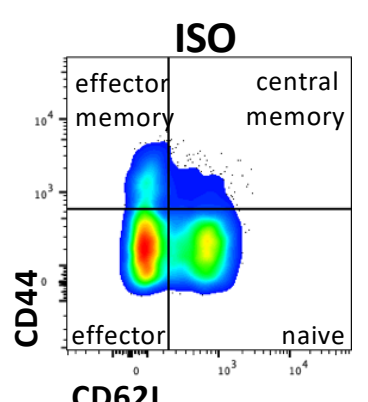

CD62L

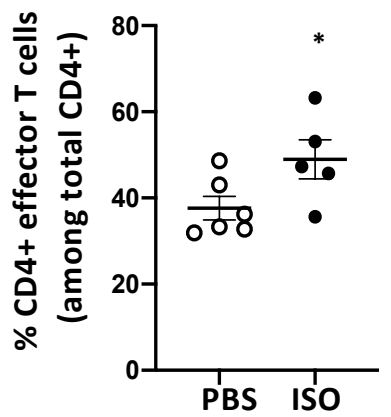


bioRxiv preprint doi: https://doi.org/10.1101/2020.02.27.962696; this version posted March 5, 2020. The copyright holder for this preprint

(which was not certified by peer review) is the author/funder, who has granted bioRxiv a license to display the preprint in perpetuity. It is

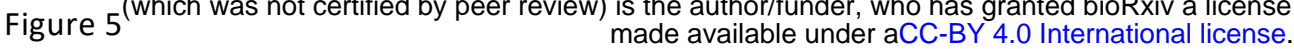

A

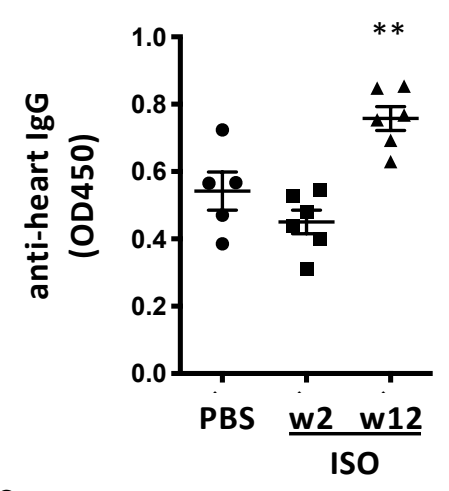

C

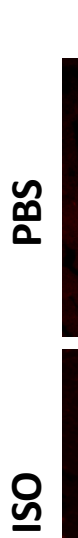

B

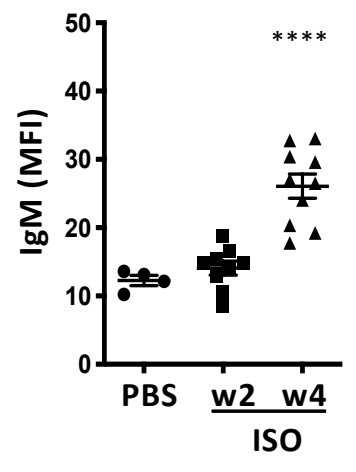

